\title{
PROCESSAMENTO DA CARNE DO JACARÉ DO PANTANAL (Caiman crocodilus yacare) ${ }^{1}$
}

\author{
Pedro Fernando ROMANELLI ${ }^{2, *}$, Roseani CASERI ${ }^{3,}$ José Francisco LOPES FILHO ${ }^{4}$
}

\section{RESUMO}

Trata-se de um estudo de algumas formas de processamento da carne de jacaré do pantanal como uma alternativa de consumo, de uma forma não convencional, da carne dessa espécie. Testa-se, ao mesmo tempo, a utilização de carne de cortes normalmente descartados tais como o tronco e os membros. Dessa forma relatam-se os seguintes processamentos: produtos de salsicharia não embutidos (tipo hambúrguer), carne em conserva (enlatado), carne curada e não cozida (defumada) e produto curado e cozido (tipo apresuntado). Avaliase a qualidade dos produtos através da análise sensorial e mede-se estatisticamente o grau de sua aceitação.

Palavras-chave: jacaré do pantanal; Caiman crocodilus yacare; processamento de carne.

\section{SUMMARY}

MEAT PROCESSING OF PANTANAL ALLIGATOR (CAIMAN CROCODILUS YACARE). This study considers different ways of processing alligator swampland meat as an alternative of consumption in a non conventional way for that species. It also evaluates the utilization of the meat coming from parts normally discarded such as muscle of the trunk and membranes. The following processes were accomplished to reach the objective: non sausage products (type hamburger) preserved meat (canned), non-cooked cured meat (smoky), and cured cooked product (type ham). The quality of the products was evaluated through sensorial analyses and the data were submited to statistical treatment to determine the acceptance degree.

Keywords: pantanal alligator; Caiman crocodilus yacare; meat processing.

\section{1 - INTRODUÇÃO}

Entende-se como produtos cárneos processados ou preparados aqueles cujas características originais da carne fresca foram alteradas através de tratamentos fisicos e/ou químicos. O processamento da carne fresca visa à elaboração de novos produtos e, por sua ação sobre enzimas e microrganismos de caráter degradativo, prolonga a vida-de-prateleira. Ele não modifica de forma significativa as qualidades nutricionais originais, mas atribui características organolépticas como, cor, sabor e aroma, próprias de cada processo [6, 9]

Estudos recentes mostram que a carne fresca do jacaré do pantanal tem boa aceitação, conforme resultados de análises sensoriais [11]. No mesmo trabalho, na avaliação das propriedades funcionais das proteínas da carne, as quais denotam o potencial tecnológico, demonstram ser altamente promissoras para a elaboração de derivados. Essa aceitação da carne do jacaré está também atestada nos registros de consumo no Brasil em restaurantes especializados e legalizados, alcançando em 1999 aproximadamente 30 toneladas, a um preço em torno de dez dólares americanos o quilo**.

Dessa forma, baseado no potencial da carne e na importância de complementar alguns conhecimentos tecnológicos para o melhor aproveitamento da espécie, para que seja uma alternativa de consumo de carne não convencional, foi propósito deste trabalho, proceder ao processamento da carne de jacaré e aquilatar a qualidade dos produtos com base em uma avaliação sensorial de aceitação.

Este estudo visa também o aproveitamento de cortes não convencionais, tais como o do tronco e o dos membros; estes possuem uma relação carne/osso superior ao do tronco, conforme ficou demonstrado [11]. Isso poderá estimular o aproveitamento destes cortes considerados não nobres e conseqüentemente levar a um aproveitamento mais completo da espécie. Os processamentos realizados foram os seguintes: produto de salsicharia não embutido (tipo hambúrguer), de grande consumo popular e de baixo custo; carne em conserva (enlatada), submetida a um forte tratamento térmico, em latas hermeticamente fechadas; carne curada não cozida (defumada), considerada nobre e de boa aceitação entre os consumidores; produto curado cozido (tipo apresuntado), de valor agregado alto devido à cor vermelha, à aparência agradável e à maciez.

\section{2 - MATERIAIS E MÉTODOS}

Utilizaram-se os cortes de 05 (cinco) jacarés machos, de 16,5 e 20,9kg, da espécie Caiman crocodilus yacare, nascidos em cativeiro, filhos de pais selvagens e coletados com autorização do IBAMA. Abatidos com tiro de revólver na cabeça entre os olhos, foram submetidos à lavagem preliminar com água abundante; sangria na

\footnotetext{
${ }^{1}$ Recebido para publicação em 16/05/01. Aceito para publicação em 19/11/01.

${ }^{2}$ Prof. Assistente Doutor Depto de Engenharia e Tecnologia de Alimentos, UNESP, CEP 15054-O00, São José do Rio Preto, SP. E - mail: romaneli @, eta.ibilce.unesp.br

${ }^{3}$ Estagiária, aluna de graduação do Depto de Engenharia e Tecnologia de Alimentos. Bolsista CNPq/PIBIC.

${ }^{4}$ Prof. Assistente Doutor - Depto de Engenharia e Tecnologia de Alimentos, UNESP, CEP 15054-O0O, São José do Rio Preto,SP.

* A quem a correspondência deve ser enviada.

** Informações colhidas junto a MULTICARNES COMERCIAL LTDA. Comércio de carnes de suínos, bovinos, ovinos, aves, coelhos e carnes exóticasSão José do Rio Preto /SP, 1999/2000.
} 
vertical, e, já no laboratório, procedeu-se à retirada do couro e a uma desossa manual. Posteriormente se fizeram quatro cortes primários: cabeça, tronco, cauda e membros.

Determinou -se a composição centesimal média da carne dos cortes usados para ter-se um perfil da qualidade da matéria-prima utilizada nos processamentos [3]. A metodologia utilizada nos processamentos baseouse em literatura específica [9 ].

O produto de salsicharia não embutido (tipo hambúrguer) foi elaborado a partir de uma mistura de carne picada, toucinho, ingredientes de cura e especiarias. Utilizou-se, para o preparo, proteína texturizada de soja, sal, açúcar, pimenta branca, cebola, orégano, glutamato, fosfato e ascorbato. A mistura sofreu uma prensagem e uma subseqüente moldagem, forma sob a qual foi congelada para ser submetida a ensaios posteriores.

Nesse produto foram realizados dois processamentos, utilizando-se os músculos dos membros dianteiros e traseiros Em uma das formulações, utilizou-se como matéria-prima a carne dos membros sem a adição de toucinho, buscando avaliar a qualidade do produto contendo somente carne do jacaré. No outro experimento, utilizou-se a mesma formulação mas com a adição de $20 \%$ de toucinho suíno.

Na elaboração da carne em conserva (enlatado) utilizaram-se como matéria-prima cubos de carne de $\pm 1,0 \mathrm{~cm}$, obtidos do segmento muscular do corte do tronco; o objetivo foi o aproveitamento da carne de um corte não usual do jacaré.

Os segmentos musculares do tronco foram limpos através da retirada de cartilagem do tecido conjuntivo, da membrana visceral e da gordura aparente. Depois da permanência em salmoura a $25 \%$ por 30 minutos, fez-se um branqueamento da carne (vapor por 5 minutos), defumação com fumaça por 40 minutos, acondicionamento em latas com adição de óleo de soja como líquido de enchimento, seguido de recravação das latas. A esterilização em autoclave foi realizada a $121^{\circ} \mathrm{C}$ por 20 minutos.

Para o controle no processamento, de alterações de origem microbiológica as latas com a carne processada foram submetidas a um teste de esterilização, que constituiu da incubação em estufa a $37^{\circ} \mathrm{C}$ e a $45^{\circ} \mathrm{C}-55^{\circ} \mathrm{C}$ durante 10 a 15 dias. [10].

Depois deste período, garantida a qualidade técnica e microbiológica, a carne foi submetida à avaliação sensorial.

Dentro da tradição do processo de defumação, para o preparo da carne curada não cozida (defumada), utilizou-se o corte da cauda do jacaré, o mais usado pelos pescadores, portanto considerado nobre, o qual, após sofrer uma rápida toalete (retirada da gordura aparente e cartilagens), foi submetido ao processo de cura, com os ingredientes: sal, açúcar, páprica, antioxidante e nitrito, por aproximadamente 24 horas. Posteriormente procedeu-se à defumação, utilizando-se a combustão incompleta da serragem da madeira mogno (Figura1).
A cauda defumada foi acondicionada em sacos plásticos e armazenada durante 24 horas em câmara fria $\left(5-10^{\circ} \mathrm{C}\right)$ para, posteriormente, ser submetida à avaliação sensorial.

\section{ABATE}

$\downarrow$

SEPARAÇÃO DO CORTE DA CAUDA

$\downarrow$

TOALETE

$\downarrow$

INJEÇÃO/IMERSÃO DE SAL DE CURA

$\downarrow$

DESENVOLVIMENTO EM CÂMARA FRIA (24 horas)

$\downarrow$

DEFUMAÇÃO (serragem, $\sim 60^{\circ} \mathrm{C}, 8$ horas)

FIGURA 1. Fluxograma das etapas da defumação do corte da cauda

A expressão "produto curado cozido" aqui utilizada se deve ao fato de que o produto obtido com músculos do tronco do jacaré foi elaborado com as características tecnológicas do apresuntado (de carne suína).

A produção seguiu as etapas normais de elaboração de presunto, conforme ilustra a Figura 2.



FIGURA 2. Fluxograma do processamento do produto curado cozido (tipo apresuntado) 
Para a avaliação sensorial dos produtos, elaborouse um teste de aceitação, usando-se uma escala hedônica de 7 pontos $[1,8]$, conforme mostra a Figura 3. Os testes foram realizados nos laboratórios de análise sensorial como grupos de 40 a 50 provadores não treinados. Formada de alunos, professores e funcionários da Universidade, a equipe de provadores variou de sessão para sessão.

No caso do aglomerado de carne (tipo hambúrguer), após fritura (em óleo de soja), tal como hambúrguer comercial, foram servidos aos provadores blocos de aproximadamente $1,5 \mathrm{~cm}$ de lado.

Para o enlatado, os ensaios foram realizados após a liberação do teste de esterilização, onde as latas foram abertas e o conteúdo analisado em seus aspectos organolépticos, tais como: aparência, cor, aroma, além do teste de aceitação.

A carne curada não cozida (defumada) foi servida em tabletes fritos (em óleo de soja), e o produto curado cozido, tipo apresuntado, foi oferecido em cubos de aproximadamente $2 \mathrm{~cm}$ de lado. As amostras foram servidas aos provadores em cabines com luz vermelha.

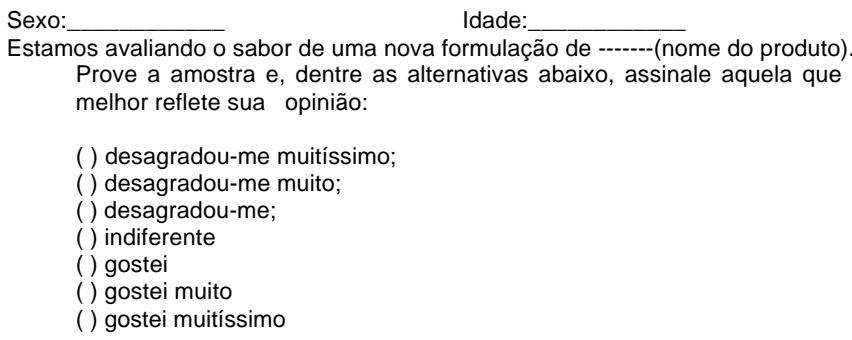

Quais as razões que o levaram a essa resposta? Comentários:

FIGURA 3. Modelo da ficha de avaliação sensorial de aceitação, quanto ao sabor, da carne de jacaré processada.

Para a comparação dos resultados obtidos, foram feitas análises de variança e aplicou-se o teste de Tukey para avaliar a diferença entre as médias utilizando-se o programa Statistica.***

\section{3 - RESULTADOS E DISCUSSÃO}

\section{1 - Aglomerado de carne picada e gordura. (tipo hamburgúer)}

A Tabela 1 mostra as características da matériaprima utilizada para a elaboração do aglomerado de carne picada e gordura.

$\mathrm{Na}$ formulação sem a adição de gordura, observouse após a fritura que as peças enformadas mais grossas tinham melhor aparência. De uma maneira geral, os aglomerados apresentavam características visuais bem próximas as dos tradicionais hambúrgueres comerciais de frango, com boa liga, embora com o aroma não muito bem aceito de carne selvagem ("estranho", "esquisito").
TABELA 1. Composição química média* da mistura da carne (membros dianteiros e traseiros)

\begin{tabular}{lllll}
\hline $\begin{array}{l}\text { Porcentagem } \\
\text { (g/100g amostra) }\end{array}$ & $\mathbf{N}$ & $\mathbf{X}$ & $\mathbf{S}$ & $\boldsymbol{\mu} \mathbf{( 9 5 \% )}$ \\
\hline $\begin{array}{l}\text { Proteínas } \\
(\mathrm{N} \mathrm{X} \mathrm{6,25)}\end{array}$ & 9 & 19,44 & 0,226 & $\mathrm{X} \pm 0,14$ \\
Colágeno & 6 & 1,83 & 0,037 & $\mathrm{X} \pm 0,29$ \\
Umidade & 8 & 75,36 & 0,679 & $\mathrm{X} \pm 0,47$ \\
Lipídeos Totais & 8 & 4,19 & 0,268 & $\mathrm{X} \pm 0,18$ \\
Cinzas & 7 & 1,0 & 0,036 & $\mathrm{X} \pm 0,027$ \\
\hline
\end{tabular}

*De 05 animais

Onde:

$\mathrm{N}=$ número de observações

$\mathrm{X}=$ média das determinações

$\mathrm{S}=$ desvio padrão

$\mathrm{m}=$ intervalo com $95 \%$ de confiança.

$\mathrm{Na}$ análise sensorial o produto obteve uma média de aceitação de 4,84 \pm 0,94 (na escala hedônica de 1 a 7 , com $\mathrm{N}=38$ ), porém observou-se um grande número de comentários desfavoráveis, principalmente do tipo "duro" e "apimentado".

O tempero foi uma variável de fácil mudança; o problema estava na textura. A alternativa encontrada foi a adição de $25 \%$ de toucinho suíno. Com essa mudança,

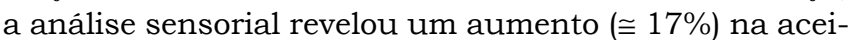
tação do produto (média de 5,64 \pm 0,81 - Tabela 4), não mais merecendo as observações desfavoráveis da primeira formulação. Neste segundo teste, os provadores não foram os mesmos do primeiro ensaio.

Uma outra alternativa para a melhoria da maciez seria a substituição de parte da gordura suína por proteína texturizada de soja, aumentando a capacidade de retenção de água (CRA) pelo produto.

Para a indústria, o percentual de ligantes (proteínas, e/ou gordura) adicionado representa uma outra vantagem que é o barateamento do custo. O hambúrguer, de algumas marcas existentes hoje no mercado, é composto de até $50 \%$ de proteína vegetal, ou toucinho e sua qualidade não é afetada, sendo muito bem aceita pelo consumidor.

Pela qualidade nutricional, pela recuperação de proteínas de subprodutos, de material de descarte, ou de cortes de segmentos musculares não usuais, a elaboração de um produto de baixo custo e de boa aceitação popular, como é o caso dos produtos de salsicharia não embutido, parece ser um procedimento economicamente viável. De fato, observa-se em trabalhos recentes que o hambúrguer elaborado com $100 \%$ de carne de segunda, tipo costela e pescoço de caprino, ou então adicionado de 25 e $50 \%$ de carne bovina, tem, nos dois casos, muito boa aceitação [2].Tem-se notícia de hambúrguer também com boa aceitação produzido de polpa lavada e temperada de pescados de água doce [13], ou de hambúrguer de diferentes sabores a partir da base protéica de pescada (BPP) [14]; sabe-se de hambúrguer de carne moida de carpa em diferentes condições de lavagem e

***Statistica for Windows: Computer programa manual. Tulsa: Stat Soft, 1995. 01 disquete 3/1/2 pol. 
estocagem [12], ou ainda hambúrguer de bovinos/suínos e frangos servindo de suporte para estudos sobre a influência do sal iodado na oxidação lipídica [15].

\section{2 - Carne em conserva (enlatado)}

Para a elaboração da carne em conserva, apresentamos na Tabela 2 as características da matéria-prima utilizada no processo.

TABELA 2. Composição química média* da mistura dos segmentos musculares do corte do tronco.

\begin{tabular}{lcccc}
\hline $\begin{array}{l}\text { Porcentagem } \\
\text { (g/100g amostra) }\end{array}$ & $\mathbf{N}$ & $\mathbf{X}$ & $\mathbf{S}$ & $\boldsymbol{\mu ( 9 5 \% )}$ \\
\hline $\begin{array}{l}\text { Proteínas } \\
(\mathrm{N} \times 6,25)\end{array}$ & 8 & 18,39 & 0,480 & $\mathrm{X} \pm 0,33$ \\
Colágeno & 6 & 1,78 & 0,036 & $\mathrm{X} \pm 0,029$ \\
Umidade & 8 & 75,59 & 0,793 & $\mathrm{X} \pm 0,55$ \\
Lipídeos Totais & 7 & 5,05 & 0,111 & $\mathrm{X} \pm 0,08$ \\
Cinzas & 7 & 1,05 & 0,055 & $\mathrm{X} \pm 0,04$
\end{tabular}

*De 05 animais.

Onde:

$\mathrm{N}=$ número de observações

$\mathrm{X}=$ média das determinações

$\mathrm{S}=$ desvio padrão

$\mathrm{m}=$ intervalo com $95 \%$ de confiança

A avaliação sensorial da carne em conserva (de vidade-prateleira relativamente alta) mostrou que o aroma do produto foi bem aceito, tendo sido mencionadas semelhanças ao atum em lata; o mesmo não aconteceu em relação à aparência, que teve um alto grau de rejeição devido à presença de vestígios de membrana visceral aderente, de cor escura nos cubos de carne fornecidos aos provadores. Isso mostra que o processamento da carne enlatada do jacaré em alta escala, a partir de segmentos musculares ventrais, ainda necessita estudos que facilitem a retirada total das membranas viscerais em futuras linha de produção. Provavelmente, feitas essas correções, terá boa aceitação por parte do consumidor.

Durante os ensaios da análise sensorial foi observado por alguns provadores, cubos de carne que apresentavam semelhanças com toucinho suíno (segmentos musculares mais claros), motivo de recusa por alguns provadores.

O produto obteve uma nota média de 4,77 \pm 0.44 , o que corresponde a mais de $68 \%$ de aceitação, apesar dos comentários desfavoráveis complementares ao teste, tais como: "sem sabor" e "oleoso". Esses resultados evidenciam a necessidade de melhorar as caracteristicas da carne enlatada para que tenha uma aceitação mais favorável pelo consumidor.

Para sanar a rejeição à cor, a alternativa seria a produção em conserva de carne moída, tipo "Corned Beef", o que ocasionaria uma homogeneização da cor.

A literatura faz referência à carne de camelo, exótica e/ou selvagem, submetida a um tratamento térmico mais suave (cozimento comum, de consumo rápido) como forma alternativa de consumo, a qual obteve, juntamente com a defumação, uma das maiores pontuações na avaliação sensorial, no teste de preferencia [18].

\section{3 - Carne curada não cozida (defumada)}

As características da carne da cauda de 5 animais usadas para o processo de defumação são mostradas na Tabela 3 abaixo.

TABELA 3. Composição química média* da mistura da carne (cauda)

\begin{tabular}{lcccc}
\hline $\begin{array}{l}\text { Porcentagem } \\
\text { (g/100g amostra) }\end{array}$ & $\mathbf{N}$ & $\mathbf{X}$ & $\mathbf{S}$ & $\boldsymbol{\mu}(\mathbf{9 5 \%})$ \\
\hline $\begin{array}{l}\text { Proteínas } \\
(\mathrm{N} \times 6,25)\end{array}$ & 9 & 18,52 & 0,571 & $\mathrm{X} \pm 0,37$ \\
Colágeno & 6 & 1,86 & 0,062 & $\mathrm{X} \pm 0,05$ \\
Umidade & 9 & 74,72 & 0,559 & $\mathrm{X} \pm 0,36$ \\
Lipídeos Totais & 7 & 5,36 & 0,362 & $\mathrm{X} \pm 0,27$ \\
Cinzas & 7 & 1,03 & 0,079 & $\mathrm{X} \pm 0,06$ \\
\hline
\end{tabular}

*De 05 animais

Onde:

$\mathrm{N}=$ número de observações

$X=$ média das determinações

$\mathrm{m}=$ intervalo com $95 \%$ de confiança.

No teste de aceitação, quanto a sabor e demais sensações sensoriais, a carne defumada obteve uma média de $5,45 \pm 0.274$, que corresponde a $78 \%$.

Verificou-se que os aspectos organolépticos de cor e aroma foram bem aceitos entre os provadores. Nesse ensaio, os adjetivos desfavoráveis mais presentes foram "duro" e "salgado", que representam aproximadamente $54 \%$ dos comentários adicionais.

A defumação parece ser um auxiliar valioso como forma alternativa de consumo de produtos cárneos exóticos e ou selvagens. Recentemente na Etiópia a carne de camelo foi avaliada, de uma forma sensorial com teste de preferência, em três (03) diferentes formas de consumo: salga, cozimento e defumação. Os resultados mostraram que o produto defumado, juntamente com o produto cozido, recebeu as maiores notas dos provadores [18].

\section{4 - Produto curado cozido (tipo apresuntado)}

O perfil da composição química da matéria-prima utilizada é a mesma já apresentado na Tabela 2. Durante a apresentação das amostras aos provadores para avaliação, pôde-se constatar aroma agradável de presunto, bem aceito, mas, ao contrário, verificou-se rejeição à aparência do produto (aspecto, cor). A massa apresentou boa liga e sem a presença de furos, mas houve falta de uniformidade na cor (mistura de segmentos musculares). O resultado final foi uma cor esbranquiçada lembrando toucinho suíno, não muito atraente, causada por alguns segmentos musculares, o que determinou repulsa a muitos provadores. Mas no teste de aceitação o produto apresentou nota média de 4,54 \pm 
0.295. Os comentários desfavoráveis foram do tipo "cor ruim", "duro" e "sem sabor". No caso da coloração, sente-se a necessidade de adição de um corante para a obtenção de uma cor mais homogênea e atraente.

Por serem os produtos curados cozidos (tipo presunto e apresuntado), de grande aceitação, são também bastantes estudados. Com isso, encontram-se na literatura vários trabalhos sobre a tentativa de melhorar ainda mais seu custo de produção, sua qualidade e/ou características sensoriais. Tentou-se o uso em apresuntados [17] de farinha de arroz como forma do aproveitamento de subproduto (grãos quebrados) em substituição à fécula de mandioca, ou a influência de fosfatos isolados, no rendimento e qualidades sensoriais do presunto tipo Cook-in [16]. Já no processamento do presunto estudou-se a difusão dos sais de cura [7], e os efeitos da suspensão dos músculos pela pelvis [4], e, como é o caso de nosso trabalho, procurou-se processar a carne de avestruz, como forma de agregar valores em carne de animal selvagem, elaborando-se presunto [5].

O acompanhamento estatístico da aceitação do processamento da carne do jacaré do pantanal é mostrado nas Tabelas 4 e 5 abaixo.

TABELA 4. Análise de variância (a nível de 5\%)

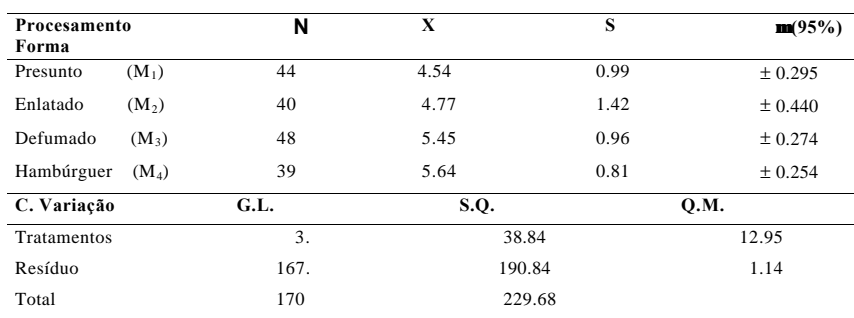

Onde:

$\mathrm{P}=8,38$

TABELA 5. Teste de Tukey

\begin{tabular}{|c|c|c|c|}
\hline \multicolumn{4}{|c|}{$\begin{array}{l}\text { Valores de } \Delta \text { ( Diferença mínima significativa-d.m.s.) para as comparações entre as } \\
\text { médias }\end{array}$} \\
\hline $\mathbf{M}_{1}$ & $\mathbf{M}_{2}$ & $\mathbf{M}_{3}$ & $\mathbf{M}_{4}$ \\
\hline $\mathbf{M}_{1}$ & $.6066^{\mathrm{NS}}$ & $.5795^{*}$ & $.6106^{*}$ \\
\hline $\mathbf{M}_{2}$ & & $.5944^{*}$ & $.6248^{*}$ \\
\hline $\mathbf{M}_{3}$ & & & $.5986^{\mathrm{NS}}$ \\
\hline $\mathbf{M}_{4}$ & & & \\
\hline
\end{tabular}

Onde:

Valores assinalados com NS não diferem entre si (nivel de 5\%

Valores assinalados com asteriscos diferem entre si (nivel de $5 \%$

Os resultados estatísticos da análise sensorial mostram que não existem diferenças significativas na aceitação entre o hambúrguer e o defumado, como também entre o presunto e o enlatado (Figura 4).

A Figura 4 mostra o perfil comparativo do grau de aceitação das 4 formas de processamento realizadas, onde foi possível observar que, em todos eles, a aprovação situou-se acima de $50 \%$, sendo que o aglomerado tipo hambúrguer obteve média de aceitação da carne curada não cozida (defumado). Da mesma forma, o tipo apresuntado teve o mesmo grau de aceitação do que a carne enlatada.Esses resultados mostram a viabilidade técnica de se elaborar derivados da carne do jacaré como formas alternativas de consumo. Mostram, também, a necessidade de correções em determinadas formulações para melhorar o grau de aceitação.

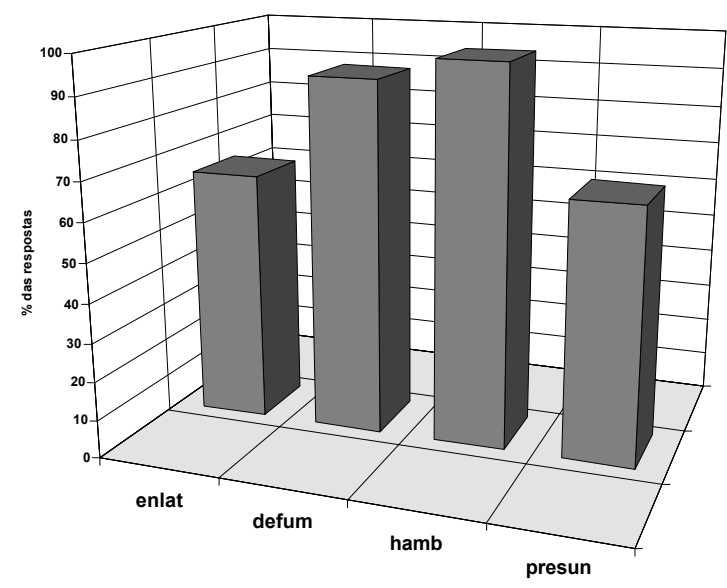

FIGURA 4. Percentual do grau de aceitação favorável dos quatro produtos processados

\section{4 - CONCLUSÕES}

De um modo geral, o hambúrguer adicionado de toucinho suíno foi muito bem aceito, porém sua textura rija e o excesso de condimentos em seu tempero propiciaram um número relativamente alto de comentários desfavoráveis.

Quanto ao enlatado, durante o preparo encontrouse dificuldade na retirada das membranas dos músculos ventrais do corte do tronco comprometendo em parte a sua aparência, requerendo, portanto, estudo de otimização. Uma melhor aceitação pode ser conseguida com a homogeneização da cor da carne, através da moagem da mesma, processando-se carne tipo "Corned Beef".

Para a melhora da defumação, um pré-cozimento anterior pode fazer com que a peça fique um tempo menor exposta à defumação, evitando o ressecamento. Assim, a defumação serviria apenas para dar um acabamento de cor e de aroma, característico de produto de defumação.

No caso do presunto, o sabor deverá requerer um tempo maior de contato entre a massa e o sal de cura (injeção/imersão), o que deve aumentar a difusão de sais. E a textura, um cozimento na mesma temperatura em um tempo mais prolongado.

Observa-se que, nas quatro formas de processamento realizadas (tipo hambúrguer, enlatado, defumado, e tipo apresuntado), a aprovação situou-se acima de 50\%, o que mostra a viabilidade técnica de se elaborar deri- 
vados de carne de jacaré como formas alternativas de consumo.

\section{5 - REFERÊNCIAS BIBLIOGRÁFICAS}

[1] AMERINE, M.A. PANGBORN,R.M., ROESSLER,E.B. Principles of sensory evaluation of foods. New York. Academic Press Inc., 602 p. 1965.

[2] ANA SANCHA, M. B. Pesquisadora desenvolve hambúrguer de bode. Revista Nacional da Carne, n.270, ano XXIII, Agosto, p.40-41, 1999.

.[3] CONNIFF, P.(Ed.). Official methods of analysis of AOAC International. 16. ed. Gaithersburg: AOAC INTERNATIONAL, V.1.1997.

[4\} FISHER, A. V. et al Effect of pelvic suspension on threee major leg musclles in the pig carcass and implication for ham manufacture. Meat Science, v.56, n.2, p.127- 132, 2000.

[5] FISHER, P. et al Processing and nutrition characteristics of value added ostrich products. Meat Science, v. $55, \mathrm{n} .2$, p.251- 254, 2000.

[6] FORREST, J. C.; et al Fundamentos de ciencia de la carne. Acribia, Zaragosa, 1364 p. 1979.

[7] LAUTENSCHLAGER, R. Curing raw meat products.1. How salts are diffused. Fleischwirtschaft, v.76, n.4, p.401405, 1996.

[8] MORAES, M.A.C. Métodos para Avaliação Sensorial dos Alimentos, $8^{\mathrm{a}}$ edição experimental, Campinas, SP, Editora da Unicamp, 93 p. 1993.

[9] PEARSON, A.M.;TAUBER, F.W. Processed meats, New York, VanMostrand Reinhold Company, 427p. 1984.

[10] PRANDL, O. et al. Tecnologia e Higiene de la carne. Zaragoza, Editorial Acribia, 854p. 1994.

[11] ROMANELLI, P.F. Propriedades Tecnológicas da Carne do Jacaré do Pantanal (Caiman crocodilus yacare) -Campi- nas, 1995, 140p. Tese de Doutorado, Faculdade de Engenharia de Alimentos. Universidade Estadual de Campinas (UNICAMP), 140p.

[12 SEBBEN, C.L. et al. Rendimento e Avaliação Sensorial de Hambúrgueres de Carpa (Cyprinus carpio) com diferentes Condições de Processamento e Armazenamento sob Congelamento. Bol. CEPPA, v.18, n.1, p.1-12, 2000.

[13] SIKORSKI,Z.E. Tecnologia de los productos del mar:Recursos, Composición Nutritiva y Conservación. Zaragoza, Acribia, p.29, 1994.

[14] SIMÕES,D.R.S. et al. Hambúrgueres Formulados com Base Protéica de Pescado. Ciênc. Tecnol. Aliment.,v.18,n.4, p. 414-420, 1998..

[15] TORRES,E.A.F.S. et al. Papel do sal Iodado na Oxidaçào Lipídica em Hambúrgueres Bovinos e suinos (Misto) ou de Frangos.Ciênc. Tecnol. Aliment., v.18, n.1, p.49-52, 1998.

[16] UDAETA, J. E. M. \& TERRA, N.N. Influência dos fosfatos e suas misturas no rendimento e atributos sensoriais do presunto tipo "Cooking-in". Ciênc. Tecnol. Aliment., v.15, n.3, p.279-283, 1995.

[17] WURLITZER, N.J \& SILVA, A. T. Uso da farinhas de arroz como substitutas da fécula de mandioca em apresuntado. Ciênc. Tecnol. Aliment.,v.15, n.2, p.118 - 123, 1995.

[18] ZEGEYE, A. A note on the influence of heat treatement, salting and smoking on the acceptabile of camel meat products. Meat Science, n.53, p.217-219, 1998.

\section{6 - AGRADECIMENTOS}

Os autores agradecem ao IBAMA pela colaboração prestada. 